\title{
The Analysis on the Seismic Performance of a Frame-tube Structure with Cross-layer Columns
}

\author{
Yonggui Chen ${ }^{1}$ and Kewei Ding ${ }^{2, *}$ \\ ${ }^{1}$ Anhui Electric Power Transmission and Transformation Co., Ltd., Hefei Anhui 231202, China \\ ${ }^{2}$ School of Civil Engineering, Anhui Jianzhu University, Hefei, Anhui, 230601, China \\ ${ }^{*}$ Corresponding author
}

\begin{abstract}
Taking the frame-core tube structure of a super high-rise building in Hefei as an example, this thesis undergoes a calculation of elasticity under frequent earthquakes and a comprehensive elastic-plastic analysis under rare earthquakes on this structure, testing the rationality of this structure's arrangement and the seismic performance of this structure and finding out the weak components in earthquake resistance. The related calculating results show that the design of this structure solves the problem of structure overrun and reaches the prospective target of the performance.
\end{abstract}

Keywords-super high-rise buildings; frame-core tube; cross-layer columns; seismic performance

\section{INTRODUCTION}

In recent years, the business building has a rapid development in high-rise and super high-rise structures. In order to meet the requirements of the architectural image and its usage and improve the ductility of the structure, this project adopts the concrete frame-core tube structure as the main lateral resisting system. The medium and lower parts of the tower adopt the steel-reinforced concrete column to decrease the column section and increase its anti-seismic performance. In order to meet the demand of big space of this architecture, the floor will be dug big holes and the floors are discontinuity. In this way, a great deal of cross-layer column will be formed. The complexity of the irregular structural form of the high-rise building makes the contradiction between the structural stability of architectures and the economy become increasingly prominent. It needs a lot of analysis on the structure of the architectures to solve this contradiction. According to the Code for Seismic Design of Building (hereinafter referred to as "Code for Seismic"): the irregular architectural structure with obvious weak parts that would lead to huge damage under earthquakes should take elastic-plastic deformation analysis under rare earthquakes according to the rules in this regulation. Generally speaking, the weak links in the structural weak layer will give in firstly and have plastic hinge and damages. In order to protect people's safety of life and property in the maximum limit, it needs to calculate the elastic-plastic deformation of the structure and finds out the weak points.

\section{EXAMPLES OF THE PROJECT}

\section{A. General Situation of the Project}

A commercial architecture in Hefei covers 182 thousand square metres, in which, the floor area is 124.2 thousand square metres and the underground building area is 57.8 thousand square metres. The standard layers of this project are quite regular. The outer contour is $48.1 \mathrm{~m}$ in length and 39.4 in width. The length-width ratio is 1.22:1. The direction $\mathrm{X}$ of the core tube is $16.1 \mathrm{~m}$ and direction $\mathrm{Y}$ is $26.4 \mathrm{~m}$. The tube space is $8.7 \mathrm{~m}$. There are three floors underground, the height of each floor is $5.4 \mathrm{~m}, 3.9 \mathrm{~m}, 3.9 \mathrm{~m}$. And there are 35 floors on the ground, the first and second floor are $6.0 \mathrm{~m}$, the standard floors are $4.0 \mathrm{~m}$. There are two refuge storeys which are $4.5 \mathrm{~m}$ in height. The outer curtain wall is $9.7 \mathrm{~m}$ in height. There is a big hole in the second floor. The hole links the second and third floors up in six steel-reinforced concrete columns and core tubes. The section of the cross-layer column is $1300 \mathrm{~mm} \times 1300 \mathrm{~mm}$. The seismic fortification intensity of the area that this project is in is 7. The basic earthquake acceleration value is $0.10 \mathrm{~g}$, and the division of the earthquake is the first group. The category of this area is II, the characteristic cycle is 0.35 . The seismic intensity is class one the safety is also class one. The basic wind pressure is $0.35 \mathrm{KN} / \mathrm{m}^{2}$.

\section{B. The Situation and Features of the Structure Overrun}

a) The height of this project which is $145.3 \mathrm{~m}$, belongs to the super high-rise structure and height scope of level $\mathrm{B}$ and is $12 \%$ higher than level A which is $130 \mathrm{~m}$.

b) There are amounts of cross-layer columns in this structure. The short and long columns are both used. The lateral stiffness of this structure has sudden change. It belongs to the vertical irregular structure.

c) There are big holes in the north and east of the floor on the second storey on the ground. The hole occupies 38 percent of the whole storey (over 30 percent, belonging to the partial discontinuity) and belongs to the plane irregular structure.

\section{The Fortification Target of the Seismic Performance}

According to the requirements of Core of Seismic, the fortification target of the seismic performance should reach the strength design of the "three standards". The calculation for the deformation of the big earthquake is to realize the three standards. At present, the project takes more "section two" design to realize the related fortification target. This project is super high-rise building. Besides the design for the above principle, it also needs to increase the requirement for the structural performance under the medium and big earthquakes. According to the requirement of Section 3.11 (JGJ3-2010) in Regulation for High-Rise Buildings, the structural seismic performance is divided into level 1, 2, 3, 4 and five and the performance target is divided into level A-D.

As for the complex and super-high-rise building structures, the performance target $\mathrm{B}, \mathrm{C}$ and $\mathrm{D}$ should be chosen in general. 
The selection of the three targets should comprehensively consider the fortification intensity, the irregular degree of the structure, the height of the building, the ability that the structure plays the ductile deformation, the structural costs and the various damages after earthquake as well as the difficulty of repairing.

\section{The ANALYsis On The STRUCTURAL CALCULATION}

There are two storeys under the ground. The structural calculation takes the roof of the basement as the fixing part, adopting spatial bar element as the roof beam and adopting column and the rigid-floor hypothesis for the floor. On the elastic calculation of the frequent earthquake, it adopts SETWE program to undergo the calculation analysis of the seismic response spectrum under frequent earthquakes and the elastic time-history analysis. On this basis, it adopts PUSH\&EPD program to undergo the elastic-plasticity static analysis under the rare earthquakes.

\section{A. The Analysis of the Response Spectrum under Frequent Earthquakes}

It adopts SETWE program to have a comprehensive analysis for the structure and adopts rigid-floor hypothesis for all the floors, taking the floors with big hole as elastic plate hypothesis. The direction of earthquake is bilateral seismic and the damping ratio is 7 percent.

The calculating results show: the periodic ratio is less than 0.85 , the minimum storey shear-weight ratio is less than 1.6 percent. The seismic force of the whole building is enlarged 1.079 in the direction Y. The shear-weight ratio meets the demand (the minimum ratio is 1.48 percent according to the requirement). After considering the role of accidental eccentricity and the bilateral seismic, the maximum storey displacement ratio is less than 1.4 and the maximum interstory drift. All the calculating indexes meet the requirements of the regulation, which can ensure the fortification criterion of "not being broken under small earthquake”.

\section{B. The Elastic Time-history Analysis under Frequent Earthquakes}

This project which is a super high-rise building, needs take elastic time-history analysis, comparing to the seismic response spectrum method to find out the weak layer of the structure and the lateral rigidity layer of discontinuity and enlarging seismic force on the regions in which the storey shear-weight ratio in response spectrum method is less than the elastic time-history result. This project adopts SATWE program to undergo the elastic time-history dynamic analysis and establish hierarchical model. It will also concentrate the mass of each storey on the storeys and form multi-mass elastic system and then input seismic wave to undergo dynamic time-history analysis. Thus, the displacement, speed and acceleration response of each point of this structure will be got. The structural internal force can be calculated through displacement response. According to the requirement of the three factors of the earthquake including the spectral characteristic of the region, effective peak acceleration and effective duration of the time-history curve, this project inputs three seismic wave in total, the forms of which are as shown in Figures. The curve diagrams of the storey displacement and drift are as shown in the following figures.
The main peak acceleration value of the components takes $35 \mathrm{~cm} / \mathrm{s}^{2}$.

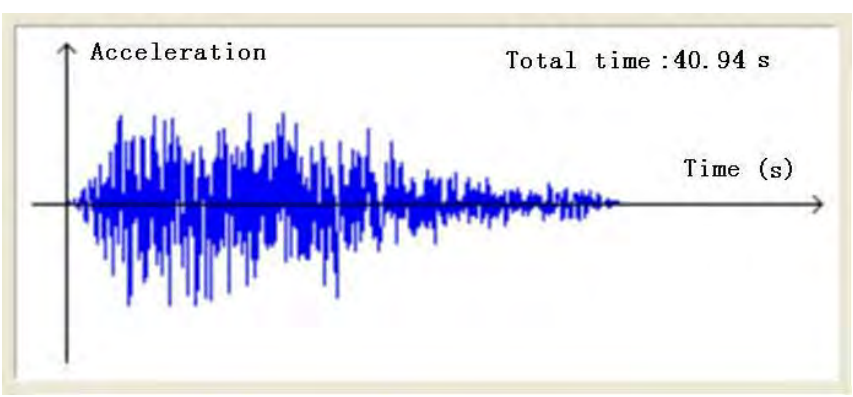

FIGURE I. MAN-MADE WAVE RZB2

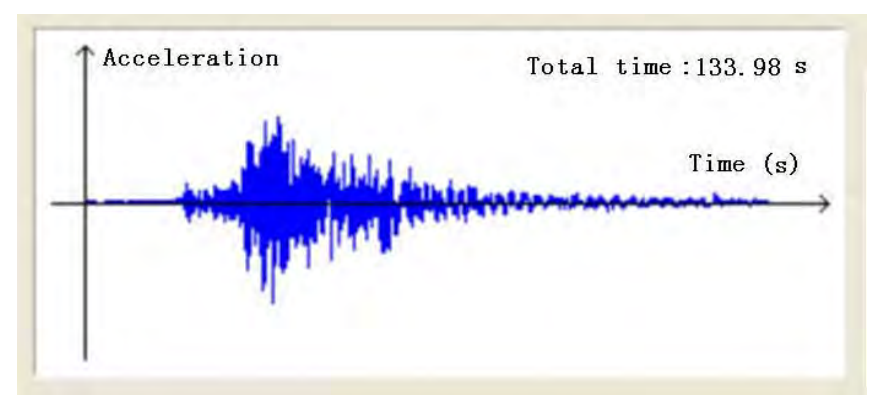

FIGURE II. NATURAL WAVE SEISMIC 2

\section{The Static Elastic-plastic Analysis under Big Earthquake}

This project adopts elastic-plastic static push-over method to undergo the elastic-plastic analysis of the whole process under horizontal earthquake. PUSH program, which is one the elastic-plastic static analysis programs developed by China Academy of Building Research, is suitable for the three dimensions finite space of the high-rise buildings with multi-layer. The cell library of the program includes two nonlinear elements including beam-column element and shear wall. It adopts fibre bundle model to simulate the one dimension components like roof beam and column and adopts microscopic method to compose element tangent stiffness directly based on the constitutive relation of concrete infinitesimal and steel infinitesimal.

\section{The Seismic Strengthening Measures For The OVERRUN STRUCTURE}

Based on the overrun situation of this project, the design of this working drawing takes the following measures:

a) The response spectrum curve under the small earthquake of this project will be taken as the code response spectrum. The maximum value of the seismic influence coefficient of the small earthquake take 0.08 and the characteristic period of the area takes $0.35 \mathrm{~s}$. When doing the calculation of the small earthquake, it considers the unfavorable combination situations including the combination of bending and torsions, 5 percent of accidental eccentricity and the bilateral seismic.

b) The concrete tube in the bottom of the strengthening area and the cross-layer columns of outer frameworks are designed as the requirement of "no yielding in medium earthquake". The calculation of the action of medium earthquake accords to 
$\mathrm{Tg}=0.35 \mathrm{~s}$ and $\mathrm{a} \max =0.23$, the code second force parameter of earthquake. The main linking beams of core tube set inter invisible supports. Thus, it is to meet the requirement of "no yielding in medium earthquake”.

c) It will undergo the calculation in STWAE and PMSAP space analysis programs--two different mechanical models. When designing the working drawing, it should make the design of the structural components according to the unfavorable results got from the calculations of the two programs.

d) It will undergo the static pushover analysis under the rare earthquakes on the structure according to the calculation and solid steel and get the maximum interstorey drift to satisfy the requirement of the code limiting value. It also strengthens the reinforcement of the restraint flange components of the wall elements which has the whole rigidity damage and the allocation of the distributing reinforcement in vertical and horizontal of the wall itself.

\section{CONCLUSION}

As for this structure of overrun super high-rise buildings, we set seismic performance target that is suitable for this project, making reasonable structural arrangement and taking strengthening measures on the key parts. The structure with cross-layer columns may become flexible column at last with the increase of plastic hinge of the common columns under big earthquakes. All in all, this project can fulfill the seismic fortification target of "no damage in small earthquake, a little damage in the medium earthquake and no collapse in big earthquake" through reasonable structural arrangement and taking strengthening measures for the key parts.

\section{ACKNOWLEDGEMENTS}

This work is supported by Key Laboratory Construction Project of Anhui Province (1501041133, AJ-CXY-KF-17-11).

\section{REFERENCES}

[1] Code for Seismic Design of Buildings. GB50011-2010[S]. Beijing: China Building Industry Press, 2010.

[2] Technical Specification for the Concrete Structure of High-Rise Buildings. JGJ3-2010[S]. Beijing: China Building Industry press, 2010.

[3] Classification Criteria for the Seismic Fortification of Construction Engineering. GB50223-2008[S]. Beijing: China Building Industry Press, 2008.

[4] Lu Xinzheng. Elastic-Plastic analysis on the Building Seismicity. China Building Industry Press: Beijing, 2009.

[5] Ding Yongjun, Yang Jie, Jia Li. Calculation and Analysis of Seismic Behavior of Frame Structure with Few Shear Walls Under Multiple Earthquake[J]. Building Structure, 2012, 42(4):76-78.

[6] Seismic Rehabilit ation of Existing Buildings. ASCE/SEC41-46 [S]. USA:American Society of Civil Engineers, 2007.

[7] No. 49 [2009]. The Notification for the Principle Decision on the Requirements of the Seismic Fortification about the Assembly Occupancies Like Schools and Hospitals[S]. Documentaries of China Seismological Bureau.

[8] ZHENG Yimin, WANG Dong. Seismic Performance Analysis of Skip-Floor Column[J]. Structural Engineering, 2012, 28(2): 89-94. 